\title{
Comparative Content Analysis of Hotel Reviews by Mass Tourism Destination
}

\author{
Leyla Atabay \\ Akdeniz University, Antalya, Turkey \\ Beykan Çizel \\ Akdeniz University, Antalya, Turkey
}

Received: 10 June 2020. Revision received: 22 September 2020. Accepted: 18 October 2020

\begin{abstract}
This article examines user-generated content (UGC) related to hotels in three different mass tourism destinations (Antalya, Majorca, and Sharm El Sheikh) that offer services with the all-inclusive system (AIS) to comparatively analyses tourists' evaluations and emotions about service components. While the study was designed with the content analysis method, text mining and sentiment analysis were used together. Customer reviews (UGC) of top hotels in three different mass tourism destinations were collected from an on-line travel review site. A total of 3588 English hotel reviews were analysed by the R program. Analysis of the reviews for famous mass tourism destination hotels in the Mediterranean region has also clearly revealed the priority service characteristics (rooms, staff, and food) and dominant emotions for hotels in all destinations in comparison. Moreover, the multiple correspondence analysis results clearly show how the emotions about the services of the hotels in three different regions diverge. Analysis results provide important clues for mass tourism destination hotels working with AIS.
\end{abstract}

Key Words: text mining, sentiment analysis, mass tourism destination, content analysis, $r$ programming, all-inclusive system

JEL Classification: M31, L83.

Reference: Atabay, L., \& Çizel, B. (2020). Comparative Content Analysis of Hotel Reviews by Mass Tourism Destinations, Journal of Tourism and Services, 21(11), 147-166. doi:10.29036/jots.v11i21.163

\section{Introduction}

Consumers view service as a set of attributes that can affect their purchase intention and perception of service quality. It is necessary to know the attributes of the components of the service of the hotels in order to provide quality service. Hotel service components which take the form of tangible and intangible qualities (Özdemir et al., 2012), has a huge effect on the quality evaluation of tourist in a highly intertwined and interactive manner. It is emphasized that with a holistic approach, hotel service components can be divided and evaluated according to their tangible and intangible features (Maric et al., 2016). Tangible service components in hotels are the appearance, equipment, personnel, etc. The relevant literature shows that hotel guests tend to consider features such as cleanliness, location, price, security, and service quality when deciding on the hotel selection. Regarding intangible qualities, what the guest finds most important when choosing a hotel is the trust in staff, the accuracy of the service, and the willingness to help guests (Maric et al., 2016).

Mass tourism, which is commonly used in many tourist destinations around the globe, is a type of tourism that has a significant market share and creates its own ecosystem. Mass tourism is a type of tourism in which products and services (accommodation, transportation, food and beverage, entertainment, sports activities, etc.) are included in a holiday package with a standard price. Destinations 


\section{JOURNAL OF TOURISM AND SERVICES}

Issuxe 21, volume 11, ISSN 1804-5650 (Online)

wwxw.jots.cz

such as Egypt, Spain, Turkey are considered to be some important mass tourism destinations in the world (Çizel et al., 2013). The pre-planned nature of mass tourism reduces risks for service providers and increases efficiency. Likewise, it enables tourists to have a safe, risk-free, and affordable holiday in an unknown destination. Since tourists coming to mass tourism destinations spend most of their time in the hotel, perceptions about tourism destinations are often evaluated through the service components of the destination hotels. This is why customer reviews of hotel service features are important to destinations.

It is seen that there are studies on the relationship between the emotions of tourists and destinations (Toral, et al., 2018). These studies emphasize three aspects of emotions. First, it is stated that emotions have an effect on the destination image, behavioural intention, and satisfaction. Second, emotions can differ according to travel stages, tourism products and services, and tourism destinations. Finally, there are both positive and negative feelings in tourism (Yüksel \& Yüksel, 2007). The expressions of tourists' likes and complaints about a destination can often be associated with many features. It is also stated that unique experiences and features satisfy tourists to a great extent (Ibrahim \& Gill 2005). These qualities can express intangible and affective qualities as well as physical qualities (Toral, et. Al., 2018). In addition to the trio of sea, sand and sun, the properties offered by the hotels are claimed to be of great importance especially in mass tourism destinations (Kozak, 2007). Poon (1993) argues that the tourism market is influenced by many different demographic, socio-economic and psychological factors such as tourists' motivations, emotions, opinions, etc. According to Tung and Ritchie (2011), tourists' emotions can clearly reflect tourist experiences. For this reason, while tourists are looking for information about a destination, they are also curious about the emotions of other experienced tourists about that destination. (Jalilvand \& Samiei, 2012). Tourist reviews also include information about hotels in a destination and the feelings of tourists (Bickart \& Schindler, 2001).

Web-based distribution channels that emerged in tourism with the development of technology allow tourists to purchase tourism-related products and services digitally and to share their comments and evaluations about products and services through these virtual platforms. User-generated content related to tourism products and services has become an essential source of information for tourists, tourism businesses and tourism researchers in recent years.

Along with the development of information and communication technologies (ICT), individuals now have a place in the virtual environment, where they can both consume and produce information. Content created in the digital world can be found in different variations such as video, photograph, and/or text. Inspection of user-generated content (UGC) affects many areas, especially marketing activities, because of the potential to shape brand perceptions through the management of UGC on various platforms (Smith et al., 2012). Especially in today's social media, UGC has fundamentally changed the information structure obtained from users, and research on user-created content has become valuable for many stakeholders (Cha et al. 2007). Researchers claim that UGC is more reliable, useful, and neutral as it is created by consumers and not by working professionals (Mir \& Rehman, 2013; Verhellen et al. 2013). In this context, potential consumers rely on content created by other users with respect to brands and products, because they have the perception that users do not have a commercial interest (Mir \& Rehman, 2013).

Although it has become easier to reach tourist evaluations with the development of ICT in recent years, it is discussed what are the most suitable methods to obtain data about the assessment of tourists, to classify and make sense of the accumulated big data. In this context, it is important to examine UGC with data mining methods (Law et al., 2009; Bach et al., 2013). The spread of UGC and the comments written by users have become the biggest indicators of tourist preferences and satisfaction, paving the way for text mining. Text mining has become one of the most used techniques in analysing the UGC (Zheng et al., 2018; Nave et al., 2018; Lau et al., 2005).

In this research, visitor reviews about hotels working with an all-inclusive concept in mass tourism destinations were examined with an inductive approach. The main purpose of the research is to obtain 


\section{JOURNAL OF TOURISM AND SERVICES}

Issuxe 21, volume 11, ISSN 1804-5650 (Online)

wwxw.jots.cz

meaningful themes and emotions from the big data accumulated in a digital environment with text mining techniques. Within the scope of the research, answers to the following research questions will be sought:

1) What are the features of the service components of the mass tourism destination hotels?

2) What are the emotions that arise from the analysis of hotel reviews according to mass tourism destinations?

3) What are the similarities and differences between the tourists' emotions about the service components of hotels operating with the same concept in different mass tourism destinations?

It is considered that this study will contribute to the current literature on UGC through the use of text mining techniques combined with sentiment and correspondence analysis in the context of the hotels with an all-inclusive concept at three different mass tourism destinations. To the best of our knowledge, there was no similar study conducted in this context. Considering that resort hotels at mass destinations receive a significant amount of reviews on various travel platforms, a lot of effort, time, and money should be invested in their management. New methods to approach review analysis could be informative and useful for hoteliers in their efforts to increase their competitiveness and effectiveness of their marketing strategies.

As for the structure of the current paper, the first part is devoted to literature review on UGC and e-WOM and data mining followed by definitions of emotions and their analysis in tourism research. The study will continue with the description of applied methodology, data collection, and techniques used to process these data. The third part presents the findings of the conducted analysis through both visual figures and reports of the same. In the conclusion part, the findings will be discussed with special emphasis on the theoretical and practical contributions of the current study.

\section{Literature review}

\subsection{Communications and Contents in User Interaction}

Studying the reasons that push people to buy a certain product or service, has led researchers to examine word of mouth (WOM) communication (Dichter, 1966). Researchers have defined WOM as informal communication between customers and tourism companies regarding the evaluation of goods and services (Singh, 1988). It is possible to express WOM with positive emotions in the context of unforgettable, dazzling experiences, negative in the context of unpleasant experiences, or neutral feelings without any weight (Anderson, 1998). Both positive and negative WOM communications can have a strong impact on consumer behaviour, enhancing business performance. The development of ICT, especially the Internet, affected how people search, disseminate and communicate information. Although electronic to mouth communication (e-WOM) has very strong ties with traditional oral to mouth communication, it offers a brand-new perspective (Al Mana \& Mirza, 2013).

In tourism industry, where it is not possible to experience the product and service before purchasing, the e-WOM effect is high for the tourists who want to purchase products or services on-line (Park et al., 2007). Moreover, it is highly possible for positive and negative opinions to direct potential consumers in e-WOM (Çakır et al., 2017). E-WOM, which facilitates the communication of consumers in on-line environments, is a kind of UGC that is displayed through environments such as social media, on-line recommendation, and forum sites. UGC is an important tool for consumers to express themselves and communicate with others on-line (Boyd \& Ellison 2007). UGC, which is defined as the sum of the ways people use social media (Kaplan \& Haenlein 2010), can be produced individually or collaboratively. UGC refers to media content created or produced by ordinary people, not by professional content managers, and predominantly distributed over the Internet (Daugherty et al., 2008). In this context, UGC \& e-WOM are closely related. However, UGC is used to express a broader concept. EWOM is considered as positive or negative statements about a product or company that is presented to 


\section{JOURNAL OF TOURISM AND SERVICES}

Issuxe 21, volume 11, ISSN 1804-5650 (Online)

wwxw.jots.cz

many people and institutions over the internet by potential, real or former customers (Henning - Thurau et al., 2004) while UGC is based on consumers' own experience. Therefore, researchers state that UGC is more reliable, useful, and neutral (Buttle, 1998; Mir \& Rehman, 2013; Verhellen, et al., 2013).

\subsection{Emotions in UGC}

Due to the nature of the services in tourism, their production and consumption occur simultaneously. Therefore, consumers rely more on hotel reviews before they experience the service, to avoid problems they may encounter later. It is very important that consumers review others' experiences and ideas before making their own purchasing decisions. Moreover, positive and negative comments and emotional expressions related to them are important in order to prevent possible situations that may affect their satisfaction with the service provider (Lee et al., 2017).

Emotions are defined, directly or indirectly, as bio-regulatory reactions aimed at promoting psychological conditions that ensure survival (Damasio, 2004). Although human emotions vary in many studies, they are generally conceptualised as positive, negative, or neutral (Watson et al., 1988; Fredrickson \& Losada, 2005; Gilbert \& Abdullah, 2004). Emotions experienced during holiday travels are more positive than negative (Zins, 2002; Nawijn, 2011). Researchers have focused on whether positive emotions have a positive effect on other people. One of the important theories, introduced by Fredrickson (1998), based on the influence of positive emotions is the "Broaden and Build" theory. Fredrickson (1998) argues that positive emotions function to expand our current range of cognitive attention and motivation beyond basic needs. In this context, Fredrickson (2001) argues that subjective well-being is an emotional state in which there is a positive superiority over essentially negative emotions. An individual with a positive mental state has more ability to broaden his horizons, which will enable him/her to take positive actions that lead to beneficial results. Individuals with a positive perspective tend to remember positive events better and are less likely to interpret uncertain events as threats than those individuals who think negatively (Sirgy, 2019). It is known that positive emotions encourage individuals to participate in the environment and activities (Yan et al. 2018). Moreover, positive emotions serve to expand the accumulation of a person's instantaneous mindset by expanding a range of thoughts and actions in any context, including tourist experiences (Sirgy, 2019).

There are many findings linking the effectiveness of negative emotions to negativity bias (Yin et al., 2014). However, there are studies proving that using negative emotions to explain the behavioural intentions of consumers is more effective than using positive ones (Yan et al., 2018). This is because negative opinions are unusual or unforeseen, they are considered to be more effective and beneficial than positive criticisms and can, therefore, provide information that is more responsive, special and valuable (Fiske, 1980). Since negative emotions may inspire individuals to pursue their own needs and take action, a person may often display positive reactions when they are in a negative state (Shields et al. 2016). Marcus and Mackuen (1993) found that people who were exposed to negative emotions were more successful than those with positive ones, remembering and conveying the events and experiences that created these negative emotions. In summary, it can be seen that negative effects enable people to concentrate more, be more careful and calm (Ma \& Li, 2016).

Research findings reveal that negative on-line reviews are more useful than positive on-line reviews when potential consumers make on-line purchasing decisions. Therefore, negative assessments provide more detection and reliable information about the service compared to positive on-line evaluations (Lee et al., 2017). Customers tend to value more negative reviews than positive reviews on TripAdvisor due to their reliability (Lee et al., 2017). If tourism recommendation sites contain a very high number of positive reviews, tourists are starting to find these types of review sites unreliable. However, it has been suggested that the value of negative comments will decrease if negative criticisms are presented with harsh and overly emotional expressions (Lee et al., 2017). However, when the reviews containing 


\section{JOURNAL OF TOURISM AND SERVICES}

Issuxe 21, volume 11, ISSN 1804-5650 (Online)

wwxw.jots.cz

negative or positive feelings are compared, it should be known that the positive side is more intense (Ullah, 2016).

In some studies, (Cajachahua \& Burga, 2017; Tromp \& Pechenizkiy, 2014), it is seen that emotions are conceptualized beyond positive and negative classification. Since different emotional classifications exist in the literature, the question arises of how to conceptualize emotions (Suttles \& Ide, 2013). Although there are a lot of classifications, many studies are based on the emotion classification approaches of Ekman (1992) and Plutchik (1980). Ekman (1992) argues that there are six different emotions: disgust, sadness, happiness, fear, anger, surprise. It is intriguing that four out of the six emotions of Ekman are negative feelings. Plutchik (1980), however, advocates the existence of 8 basic emotions: anger, disgust, fear, sadness, anticipation, joy, surprise, trust. Seemingly, the negative and positive distribution of emotions is more balanced in Plutchik's research. These two approaches are also reflected in UGC research (Serna, et al., 2016).

\subsection{Text Mining and Sentiment Analysis in Tourism Research}

Tourist reviews have become the biggest indicators of tourist preferences and satisfaction, paving the way for text mining (Zhang et al., 2018; Nave et al., 2018; Lau et al., 2005). Text Mining comes to the fore in text mining studies. Hotel reviews (Neidhardt, Rümmele \& Werthner, 2017), restaurant reviews (Gan et al., 2017; Nave, et al., 2018), visitor satisfaction (Guerreiro \& Moro, 2017; Park et al., 2016; Tao \& Kim, 2019; Aureli et al., 2017), and destination image (Dickinger \& Lalicic, 2016; Li et al., 2015; Qi et al., 2018; Wong \& Qi, 2017) have been analysed by text mining methods. Especially since 2016, text mining studies on the sharing economy have become widespread regarding reviews on platforms such as Airbnb. Along with the studies that analyse Airbnb reviews using data mining methods in the literature (Belarmino, 2019; Cheng \& Foley, 2018; Cheng \& Jin, 2019; Sun et al., 2019; Tussyadiah \& Park, 2018; Tussyadiah \& Zach, 2017), studies that examine the comments and contents of UNESCO sites (Kim et al., 2019), botanical gardens (Catahan \& Woodruffe-Burton, 2019), castles in Europe (Yagi \& Pearce, 2018) are also remarkable.

Most of the studies based on sentiment analysis are about hotel reviews (Bjørkelund, et al., 2012; Bucur, 2015; Gräbner et al., 2012; Kasper \& Vela, 2011; Kasper et. al., 2012; Marrese-Taylor et al., 2013; Markopoulos et al., 2015; Rossetti et al., 2015; Tan \& Wu, 2011). However, reviews of restaurants (Ganu et al., 2009; Zhang et al., 2011) and airlines (Misopoulos et al., 2014) were also analysed. Alaei et al. (2019) reported that some studies which used sentiment analyses preferred small datasets due to lack of human resources. However, there are some research that used 10.000.000 (Shimada et al., 2011) and 70.570.800 (Claster et al., 2013) twitter reviews, it is understood that researchers typically got data from three different sources. Those sources were social media platforms such as Twitter, on-line travel agencies such as Booking, and travel recommendation sites such as TripAdvisor. In these studies, it is revealed that programs frequently used in the text mining field, such as R, Python, Leximancer, Rapidminer, Nvivo, are preferred. In this article, for the very first time, it is aimed to examine the travel themes and emotions about the service components of the tourist comparatively by examining on-line travel reviews about hotels in mass tourism destinations with text mining techniques such as word counting, network analysis and semantic classification to process big data.

\section{Methods}

The research was conducted by following the content analysis method. Content analysis has been used for a while in disciplines such as education, communication, sociology, psychology, social psychology, documentation, health, business (Neundorf, 2002). Although there is no definite unity of definitions, it can be considered as "coding" and "theming" process with a flexible and pragmatic point 


\section{JOURNAL OF TOURISM AND SERVICES}

Issuxe 21, volume 11, ISSN 1804-5650 (Online)

wwxw.jots.cz

of view to make qualitative data systematically more understandable for qualitative content analysis (Schreier, 2014). It is stated that it is the most common method used in the analysis of documents consisting of qualitative data (Bryman, 2012). Researchers emphasise three main characteristics of qualitative content analysis (Schreier, 2014). The first characteristic is its reductive feature as content analysis helps researchers to derive more specific meanings from massive data. The second characteristic is that it is systematic. This indicates that the analysis should have comprehensive procedures of integrity. The final characteristic of content analysis is flexibility due to the fact that the coding and data summaries contain subjectivity. With these characteristics, it is considered that content analysis has an important potential for tourism research as well (Ajanovic et al., 2018).

In this research, for content analysis, data mining techniques are used because it enables easy processing of big data. On on-line platforms such as social media sites, text mining is often used to analyse UGC (Al-Daihani \& Abrahams 2016). Gathering thousands of reviews with classical "manual" methods, analysing them systematically, and extracting meaningful information from these data brings various constraints in terms of time and cost. Data mining incorporates techniques that allow processing much more data in a much shorter time (Salkind, 2010).

\subsection{Sample}

The common feature of all three tourism destinations, which are examined comparatively within the scope of the research, is that they are the preferred mass tourism destination for foreign tourists in their countries. These three destinations, which mostly work with the all-inclusive system, are in tight competition with each other in the Mediterranean region (priceoftravel.com). Antalya is one of the most important mass tourism destinations in the world working with AI System (UNWTO, 2019). Antalya hosted approximately 15 million tourists by the end of 2019. Mallorca is the most visited Spain mass tourism island with more than 10 million tourists each year. The number of international tourists visiting the Balearic Islands reached 13.7 million visitors in 2019. Sharm el-Sheik is an Egyptian mass tourism destination located in South Sinai Governorate, on the coastal band along the Red Sea. In Egypt, which hosted 11 million tourists in 2019, Sharm el-Sheik is the most visited mass tourism destination (UNWTO, 2019).

Figure 1. Data Selection

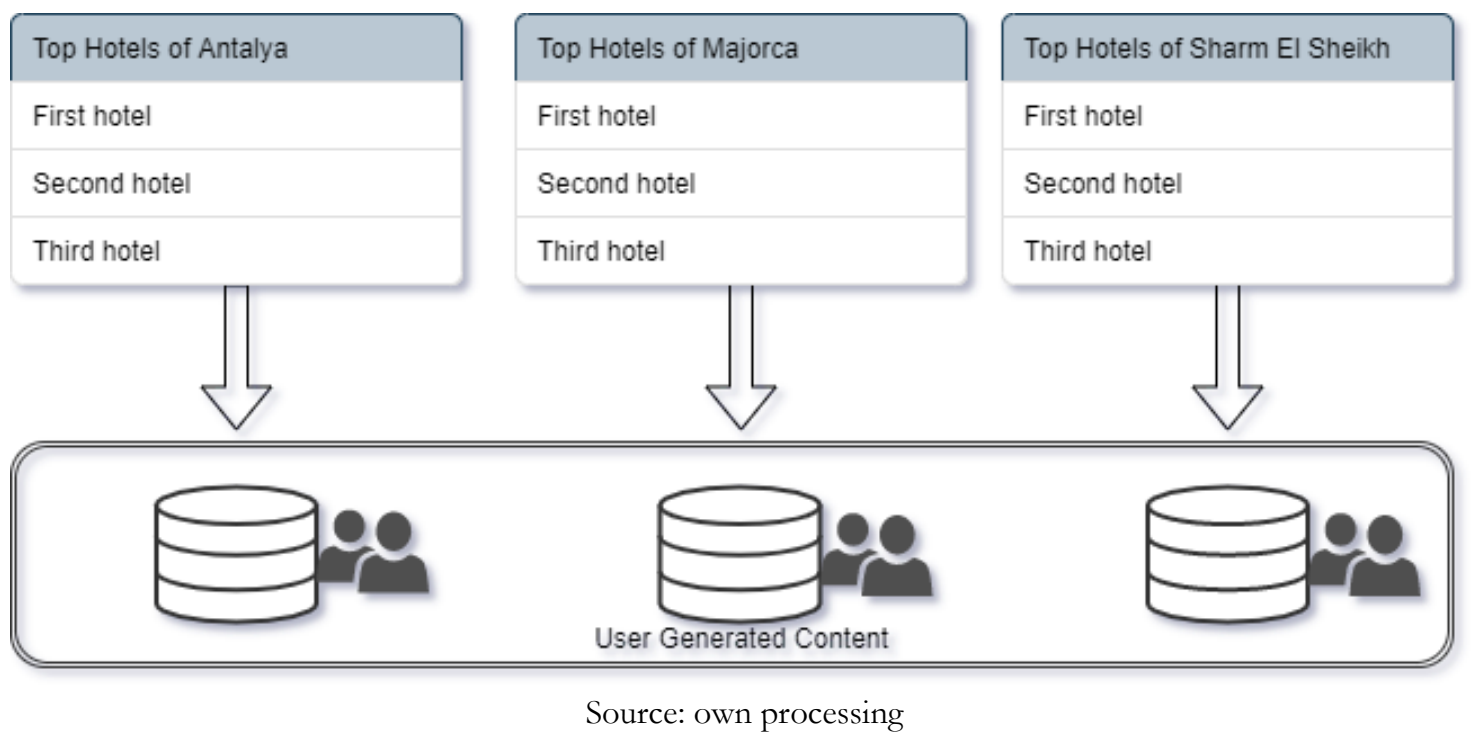




\section{JOURNAL OF TOURISM AND SERVICES}

Issuxe 21, volume 11, ISSN 1804-5650 (Online)

wwxw.jots.cz

Within the scope of the research, a total of 3588 English reviews about three hotels from each of the three mass tourism destinations, Antalya, Sharm El Sheikh, and Majorca, were analysed. The common feature of these hotels is that they are all five-star, located in mass tourism destinations that work with an all-inclusive system and with the highest user ratings. Data was taken from a travel review site with a code executed in the R program on 02.05.2019 and then converted to an Excel file. Corrupted characters, empty comments, and similar cells were cleaned during a preliminary screening. After the pre-cleaning, 1204 reviews from three hotels in Antalya, 1193 reviews from three hotels in Sharm El Sheikh, and 1191 reviews from three hotels in Majorca were taken into analysis (Figure 1).

\subsection{Data Analysis}

The rvest library in the $\mathrm{R}$ program was used in the data collection phase. Rvest is a package within the $\mathrm{R}$ libraries that makes it easy to extract (or harvest) data from HTML web pages. (blog.rstudio.com/2014/11/24/rvest-easy-web-scraping-with-r/accessdate: 10.10.2019). The rvest package (https:// cran.r-roject.org/web/packages/rvest/rvest.pdf access date: 15.11.2019) was invited to the program via RStudio and codes were written to extract data from an external source. The $\mathrm{R}$ environment's own ".rds" format was chosen as the output to prevent some data loss, corruption, and fast command execution. The raw data file obtained was then converted to Microsoft excel format with an intermediate encoding. After this process, the file with the extension ".xlsx" was opened, and corrupted characters and formal problems were corrected.

The data collected through on-line systems are not ready to be processed without being exposed to a number of transactions. It is necessary to first make the data files processed and to "train" the system at the level to analyze. "Dplyr", "tidytext", "readxl", "tm", "igraph", "wordcloud", "syuzhet", "ggplot2", "reshape2", "rio" libraries have been used to analyze the data (data1, data2, data3). First of all, clean data (cleanset) obtained from raw data (corpus) was converted to the term-document matrix. Thus, it is possible to eliminate errors such as corrupt, recurring characters, meaningless words, space problems, etc. Besides, the data must be converted to the term-document matrix to continue processing. The termdocument matrix (tdm) is a mathematical tool created to determine the frequency of terms in a document collection. In this research, terms represent each word, and documents represent each of the reviews. Following the use of TDM, four sentiment dictionaries of syuzhet package and sentiment extraction tool developed in the NLP group at Stanford were used. Syuzhet is an important and flexible package that is preferred in the literature. As part of this study, Plutchik's approach was adopted to conceptualize emotions. In recent years, lexicon-based research has shown that this approach is highly preferred. Syuzhet also use Plutchik's approach to extract sentiments from text data. Bar plots with 8 basic emotions (Plutchik, 1980) were drawn with the help of the package for each destination. Finally, multiple correspondence analysis was used to compare emotions obtained from the hotel reviews of three mass tourism destinations in the scope of the current study.

\section{Results}

\subsection{Results related to the service features of the hotels}

From Antalya data, the term-document matrix (TDM) was created from 1204 documents (reviews) and 3884 words with a sparsity rate of $99 \%$. Similarly, the same operation was performed for the Majorca region (1191 reviews and 4044 words with a sparsity rate of 99\%), and finally another TDM was created from the Sharm El Sheikh data set (1193 reviews, 3529 words with sparsity rate 99\%). After TDM was created, at least 75 times used words were listed and a word cloud was created (Figure 2). 


\section{JOURNAL OF TOURISM AND SERVICES}

Issuxe 21, volume 11, ISSN 1804-5650 (Online)

wwxw.jots.cz

Figure 2. Destinations' Hotel Word clouds

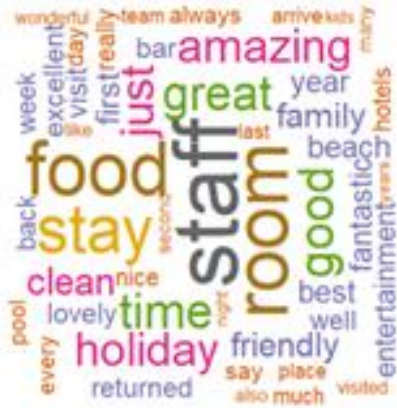

Antalya

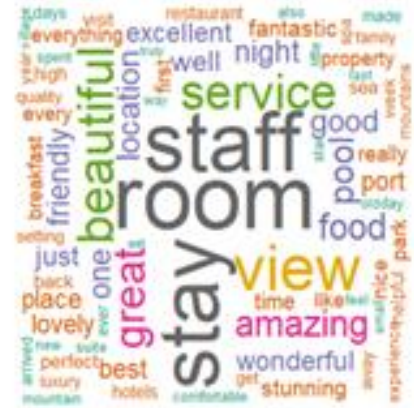

Majorca

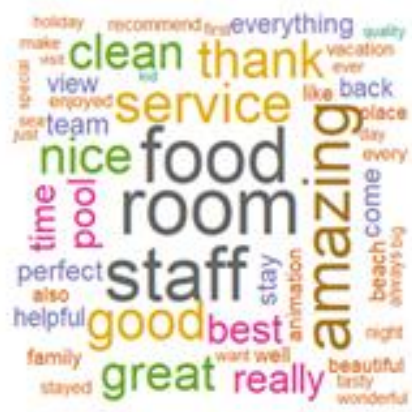

Sharm El Sheik

Source: own processing

When the data of Antalya in Figure 2 were analysed, it was determined that the words most frequently included in the reviews are staff (569), room (482), food (465) and stay (400), respectively. It is seen that words such as time, excellent, holiday, wonderful, clean, friendly, and family are also included in the reviews. When Majorca's data was analysed, it was determined that the words of room (567), staff (521), and stay (512) come to the fore. It is understood that words such as landscape, beautiful, service, great, magnificent, food, and pool are used over 200 times. Finally, in the reviews of Sharm El Sheikh, the words, room (662), food (627), staff (611), amazing (530), service (449), good (427), thank (414) and nice (406) come to the fore. The best, really, pool, time, friendly, flawless, restaurant, team, stay, perfect, come, everything, scenery, help, and back stands out as words in the reviews.

Figure 3. Network Analysis for Antalya Destination Hotels

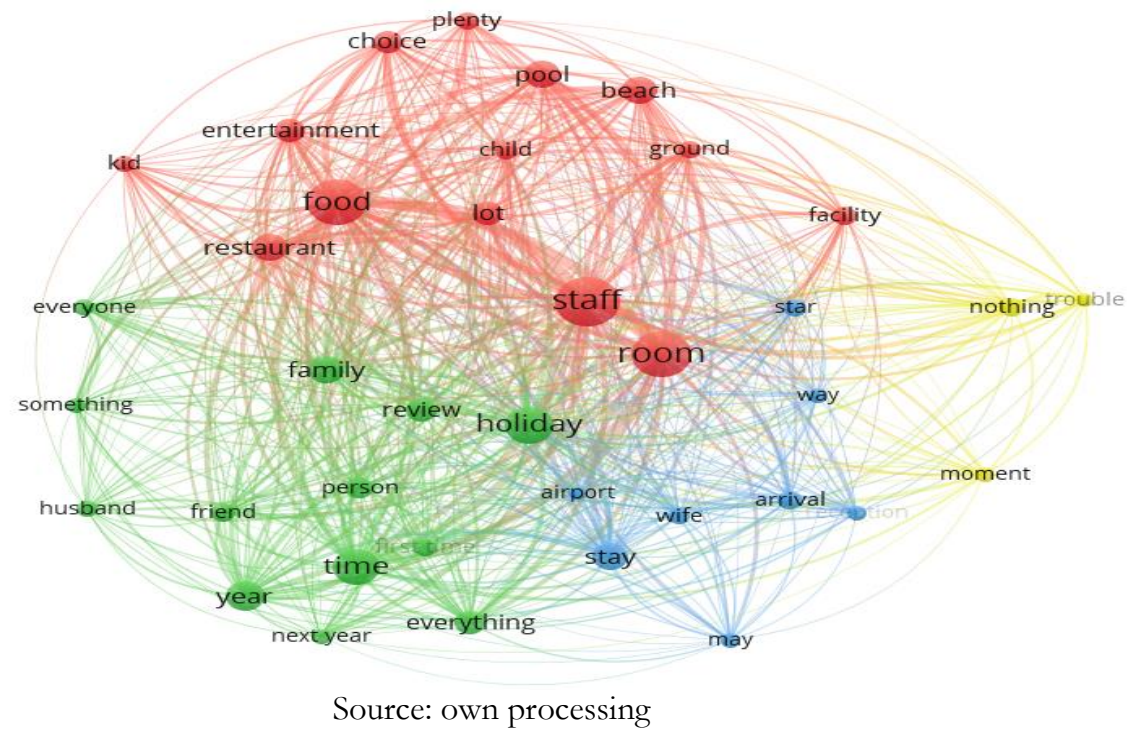

In the network analysis in Figure 3, the frequency of use of the words in the reviews made to selected hotels in the Antalya region and clusters based on the relationship they form with each other are shown. In this process, the association strength was applied as a normalisation method to the data, and the 38 most common terms were shown in the analysis. 640 connections and a total of 7109 connection strengths were determined between 38 terms. 


\section{JOURNAL OF TOURISM AND SERVICES}

Issuxe 21, volume 11, ISSN 1804-5650 (Online)

wwxw.jots.cz

In network analysis, each colour represents a set of words, and the circle sizes surrounding the words represent the frequency of use of words. As a result of the analysis, four clusters were formed. The first cluster represented by red colour contains words such as beach, child, choice, entertainment, activity, food, floor, child, many, plenty, pool, restaurant, room, and employee. In the second cluster represented by green colour, there are words such as everyone, family, first time, friend, holiday, husband, next year, person, comment, something, time and year. The third cluster, represented in blue, contains the words such as airport, arrival, may, reception, star, road, stay, and lady. Finally, in the fourth cluster represented by yellow colour words like moment, nothing and trouble were seen. In general, it can be said that the main service elements of the hotel are listed in the first cluster; the terms based on personal relationships in the second cluster; the terms related to transportation and arrival to the hotel are listed in the third cluster and the problems-based terms in the fourth cluster.

Figure 4. Network Analysis for Majorca Destination Hotels

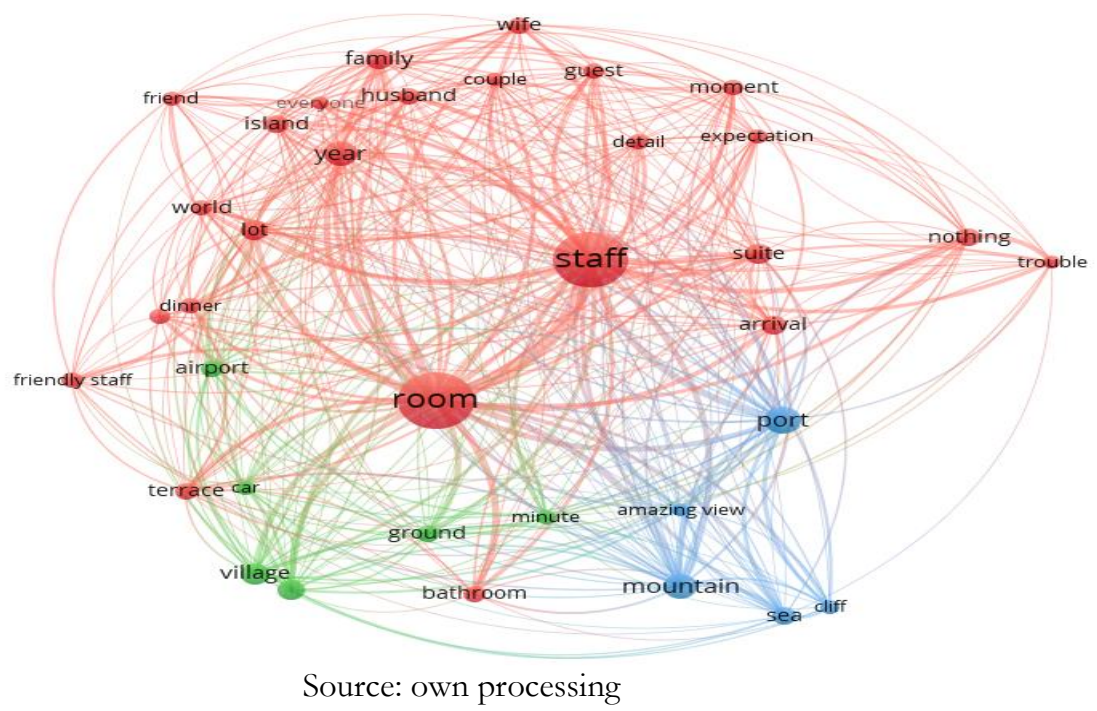

When looking at the results of network analysis for the hotels of Majorca region, applied with the same method, 36 terms that show the most common association were used. Between 36 terms, 442 connections and 2019 link strength in total were determined, resulting in a formation of three clusters. In the first red-coloured cluster there are words such as arrival, bathroom, couple, detail, dining, everyone, expectation, family, friend, friendly employee, guest, spouse, island, abundant, moment, nothing, person, room, employee, suite, terrace, problem, and spouse. The second cluster, represented by green colour, contains words such as airport, car, ground, hill, minute, and town. In the third and last cluster, represented by blue colour, words such as magnificent landscape, mountain, elevation, harbour and sea can be found. In general, it is seen that the "main service elements" belonging to the hotel are listed in the first cluster, the terms based on "transportation" are listed in the second one, and "nature and landscape" terms are listed in the third cluster.

As a result of network analysis for Sharm El Sheikh (Figure 5), 36 terms that show the most common association were visualised. Between 36 terms, 426 connections, and a total of 2022 link strengths were determined. The words in the first red cluster were wonderful stay, great view, breakfast, option, cleanliness, food, friendly staff, excellent service, high level, lobby, location, main restaurant, reception, sea and view. The second cluster, which is represented in green, includes the words such as animation team, family, first time, friends, entertainment, vacation, home, accommodation, children, kind, person, and employee. The third cluster, represented in blue, contains the words; atmosphere, entertainment, expectation, spa, star, variety, week, spouse, and year. It can be concluded that the "main 


\section{JOURNAL OF TOURISM AND SERVICES}

Issuxe 21, volume 11, ISSN 1804-5650 (Online)

wwxw.jots.cz

service elements", belonging to the hotel, are terms listed in the first, "personal relationships" in the second, while the "fulfilment of expectations" terms are listed in the third cluster.

\section{Figure 5. Network Analysis for Sharm E1 Sheikh Destination Hotels}

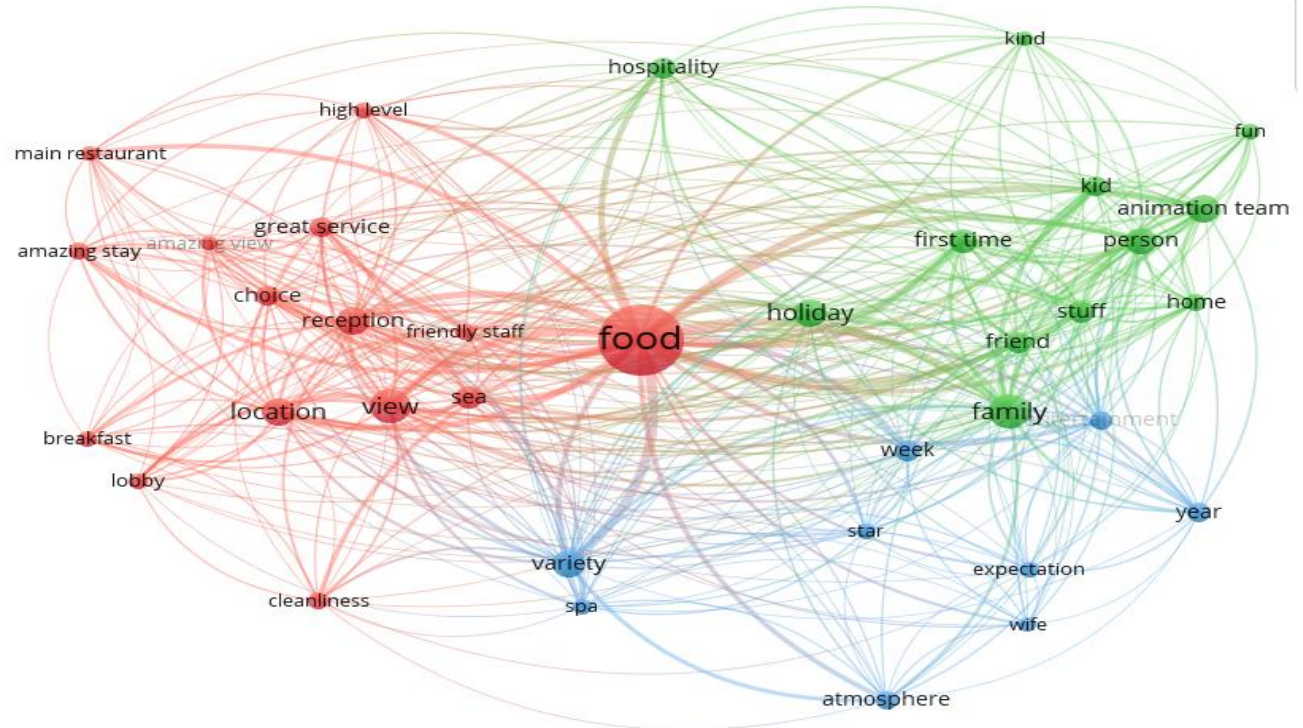

Source: own processing

\subsection{Emotions in hotel reviews}

When examining the result of the sentiment analysis of Antalya hotels, $10.3 \%$ of the reviews were expressing negative emotions such as anger $(2.2 \%)$, disgust $(1.4 \%)$, fear $(2 \%)$, and sadness $(4.7 \%)$. In addition, emotion of expectation (22.1\%), fun (30.7\%), surprise $(9.9 \%)$, and confidence $(27.1)$ are seen to come to the fore with positive reviews of $89.8 \%$ (Figure 6 ).

\section{Figure 6. Sentiment analysis of hotel reviews of Antalya Destination}

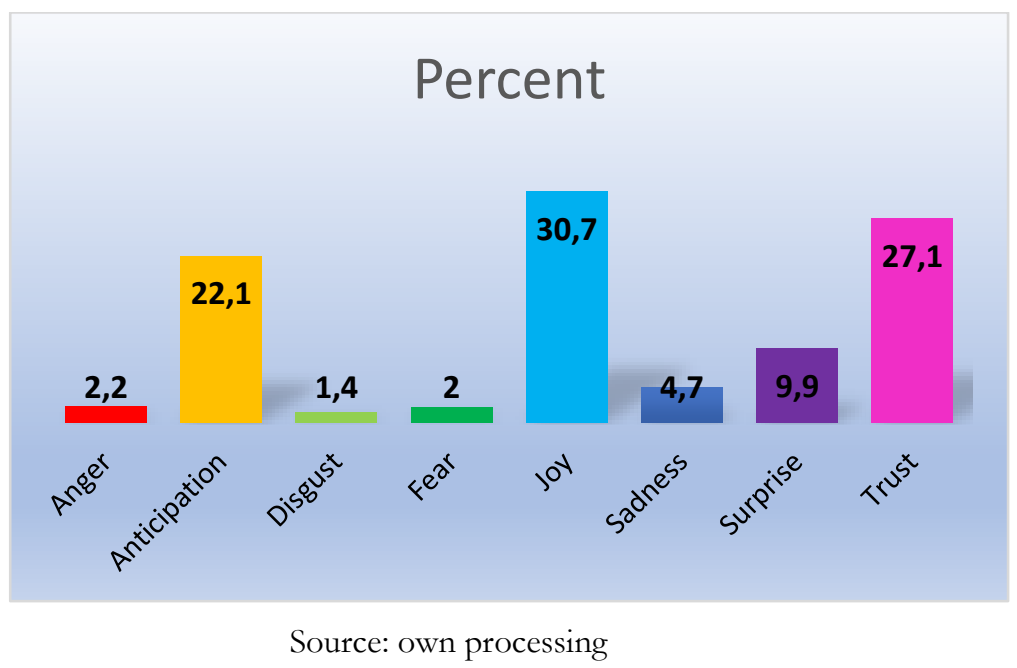

When the sentiment analysis of the reviews for Majorca destination is analysed, $13.3 \%$ of the total reviews were expressing negative emotions such as anger $(2.3 \%)$, disgust $(1.8 \%)$, fear $(2.4 \%)$, and sadness 


\section{JOURNAL OF TOURISM AND SERVICES}

Issuxe 21, volume 11, ISSN 1804-5650 (Online)

wwxw.jots.cz

(6.8\%). In addition, feelings of expectation (20.4\%), entertainment (31\%), surprise $(10.9 \%)$, and trust (24.5) appear to be prominent with positive reviews of $86.8 \%$ (Figure 7 ).

Figure 7. Sentiment analysis of hotel reviews of Majorca Destination

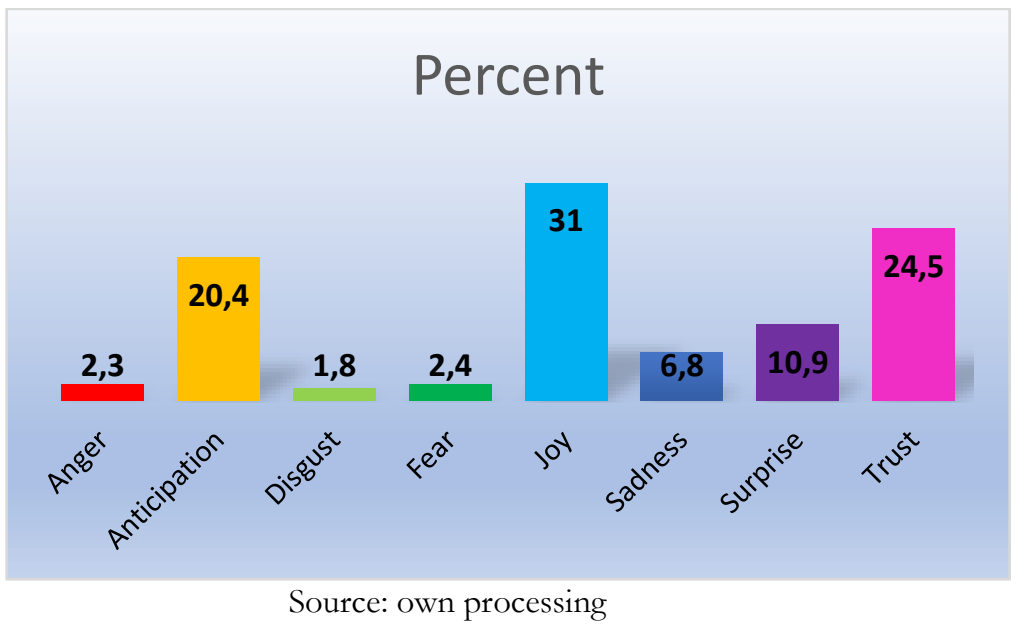

Figure 8. Sentiment analysis of hotel reviews of Sharm El Sheikh

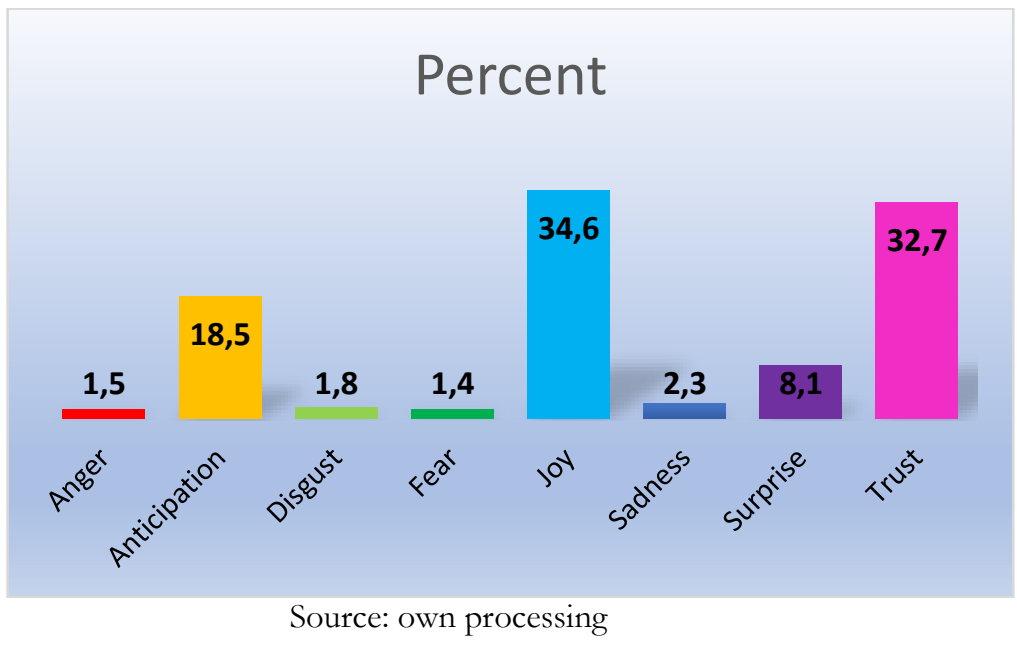

Finally, sentiment analysis of the reviews in the Sharm El Sheikh hotels, revealed that negative emotions such as anger $(1.5 \%)$, disgust $(0.8 \%)$, fear $(1.4 \%)$, and sadness $(2.3 \%)$ were found to be $6 \%$ in total reviews. In addition, feelings of expectation (18.5\%), entertainment (34.6\%), surprise (8.1\%), and trust (32.7) appear to be prominent with $93.9 \%$ positive reviews (Figure 8).

\subsection{Comparison of emotions from the hotel reviews of mass tourism destinations}

Multiple correspondence analysis (MCA) visualises the relationship between the variables put into analysis by spreading it to a multi-dimensional graph. During this process, the analysis is not based on any a priori categorisation and allows patterns to be exposed according to the specific dynamics of the data set. MCA which does not oblige the researcher to discriminate dependent independent variables prior to the analysis, is defined as an explanatory and integrative method (Clausen 1998). Variables appear as dots on maps; The distance between points indicates the extent of rationality. As the two points get 


\section{JOURNAL OF TOURISM AND SERVICES}

Issuxe 21, volume 11, ISSN 1804-5650 (Online)

wwxw.jots.cz

closer to each other, the chances of the practices measured by those two variables to act together increase. Basically, during the analysis, the matching of rows and columns in numerous frequency tables in a twodimensional field is based on the principle of reciprocity. The relative frequencies and marginal ratios of the variables are first calculated for the preparation of the map below. Then, by calculating the distance between each category, the points are positioned relative to each other in a two-dimensional graph (Clausen 1998).

Figure 9. Sentiment analysis of hotel reviews of Sharm El Sheikh

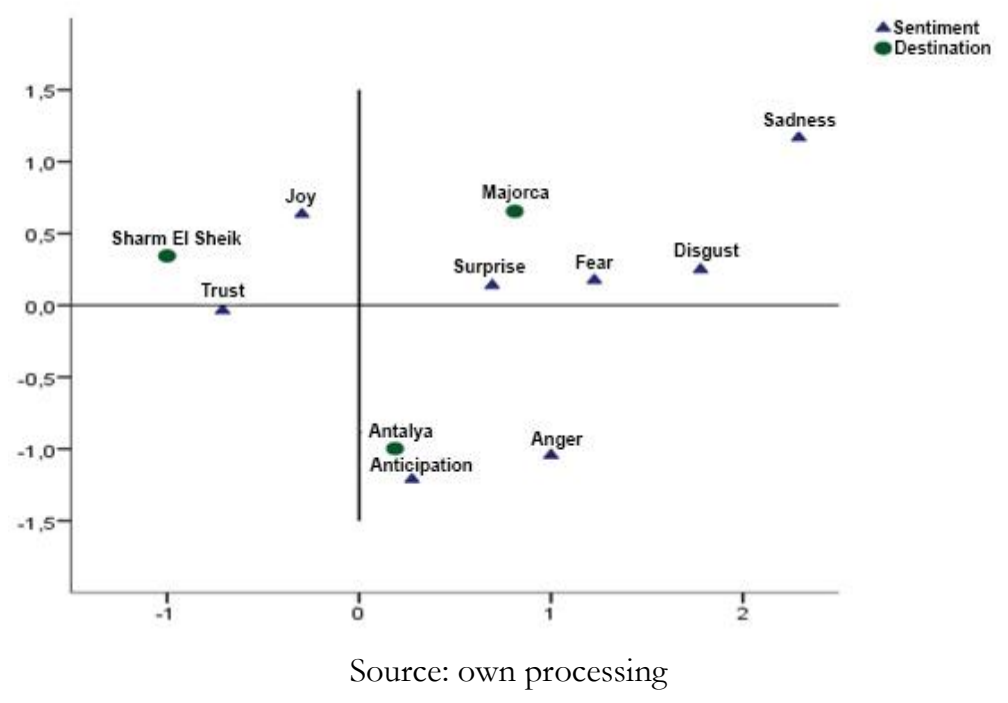

Multiple correspondence analysis shows that positive and negative emotions in the Antalya and Majorca regions are more similar (Figure 9). According to the results of analysis, it is revealed in which destinations the eight basic emotions become more evident. Comparison of destinations with the help of multiple correspondence analysis is reported on a relationship basis. In the analysis, emotions whose frequencies were determined were compared with each other in a two-dimensional graph according to the destinations. However, due to the relative frequency, the calculations were performed after weighting. Multiple correspondence analysis tries to present the meaning of encounters with the principle of induction as empirical (Clausen 1998).

\section{Discussion and Conclusion}

Hospitality companies try to stay ahead of their competitors with the help of product and service differentiation (Grasso 2014; Xiang et al., 2015). Hotel reviews or specifically UGC data were emphasized as an important factor for product and service marketing in literature (Attila., 2016; Lee et al., 2017; Li et. al., 2015; Xiang et al., 2015). However, it is necessary to discover which products and services are important for the destinations. For this reason, the study supports the literature in the discovery of products and services. Although the analysis of the reviews made for the hotels in different mass tourism destinations that work with the all-inclusive system shows that there were differences according to the destinations, the similar service features (rooms, staff, and food) for the hotels in all destinations have come to the fore. It was understood that user reviews made to hotels in Sharm El Sheikh region have more positive themes than other regions. The fact that the reviews of Sharm El Sheikh, which is one of the important all-inclusive destinations in the Mediterranean region, has more positive themes, is a proof 


\section{JOURNAL OF TOURISM AND SERVICES}

Issuxe 21, volume 11, ISSN 1804-5650 (Online)

wwxw.jots.cz

that the expectations of the visitors are significantly met. Although Antalya, Majorca, Sharm El Sheikh are similar destinations in terms of tourism type (mass tourism) and regions, it is seen that UGC data are in a class of its own. In this context, it is important to highlight unique attributes according to guest expectations. In addition to all these, it has been suggested that one of the most effective tools to measure the perceived destination image is travel review sites because reviews on such sites are purely UGC (Serna et al., 2013).

Network analysis also showed that the main service features for all destinations were gathered in the first cluster. For Antalya, Majorca, and Sharm El Sheikh regions, differences in service features in other clusters have been identified. These clusters are cumulative representations of reviews selected hotels and provide important information to hotel businesses and destinations about the complementary aspects of the service. There are two important approaches to classify emotions from text data: lexiconbased and machine learning (ML). These two approaches typically classify the emotions contained in the text as positive, negative, and neutral (Dhaoui, et al., 2017). Although the two approaches have some advantages in their own right, the main reason for adopting the lexicon-based approach in this study is that it allows to discover 8 basic emotions of Plutchik in the most risk-free way. This means no prior training is needed for data and relatively small datasets can be analyzed, unlike the ML-based approach (Taboada et al., 2011). Sentiment analysis extracted results from the evaluation of unsupervised approach by applying lexicon-based method according to basic emotions in this study. One of the important contributions of this study is that it shows the results of sentiment analysis by mass tourism destinations. The multiple correspondence analysis results showed more clearly how the three destinations differed according to sentiment analysis over hotel reviews. Findings of this analysis indicate that Sharm El Sheikh destination differs from other destinations in the context of positive emotions (Fredrickson, 1998; Sirgy, 2019). The research findings comparatively report the features of the service components of the hotels and emotions about these features in three different competing mass tourism destinations. Continuous analysis of the emotions regarding the features of the service components of the destination hotels can provide important clues about the satisfaction or dissatisfaction of the customers.

Although this study has some limitations, it has suggestions for researchers and practitioners. The scope of the study consists of five-star hotels serving in mass tourism (Antalya, Majorca, and Sharm El Sheikh) destinations. It has been an important criterion for these destinations to compete with each other in tourism products and services and to include hotels that offer all-inclusive service in the Mediterranean region. However, there are many countries offering all-inclusive services and many destinations that can be specifically evaluated in these countries. Thus, more extensive studies can be conducted on how similar products and services are evaluated in the eyes of tourists visiting different parts of the world. Moreover, it is likely that the determination of the most favourable five-star facilities in Antalya, Majorca, and Sharm El Sheikh regions will cause bias to highlight the positive characteristics. In this context, examining not only five-star hotels but also other accommodation facilities can provide useful findings. In this study, tourist emotions in other mass tourism destinations are not compared to our findings because this study is the first example that examines emotions in mass tourism regions. In this respect, it has the potential to set an example for studies examining tourist emotions in similar or different destination types.

Only one of the clustering methods (link strength and relationship) that could be preferred in social network analysis was used in our study. There are many different clustering and normalisation criteria that can be used in social network analysis. Although it is not appropriate to mention different methods since it is not directly related to the subject of our research, it is recommended to include the results of the researches to be carried out with different methods in other studies.

Sentiment analysis is one of the important tools used in this study. Syuzhet package entered the programming world a while ago and sentiment analysis can be done through different packages. Although syuzhet is an important and flexible package preferred in the literature, it is not flawless and has been subject to various criticisms like its other counterparts (https://hoyeolkim.wordpress.com/2018/02/25/the-limits-of-the-bing-afinn-and-nrc-lexicons-with- 


\section{JOURNAL OF TOURISM AND SERVICES}

Issuxe 21, volume 11, ISSN 1804-5650 (Online)

wwxw.jots.cz

the-tidytext-package-in-r/ access date: 15.12.2019). Although the results of sentiment analysis packages are constantly being improved in lexicon-based processes, it is useful to know that researchers who will use similar packages will experience some deficiencies.

The current study offers practical recommendations as well as producing academic outcomes. In addition, all accommodation companies and destinations, whether small or large, should further analyse reviews made on their products and services. It is a known fact that evaluating tourist reviews is important, but due reviews analysed in this study belong to hotels that spend high amounts of money on guest satisfaction. Hotels can increase their competitiveness by increasing the effectiveness of marketing strategies by using text mining methods. However, because of expensive solutions, reviewing the comments with long procedures has brought many difficulties. Machine learning and innovative data mining techniques can be evaluated in this context, allowing thousands of comments on hotels to be examined in a short time. Analysing hotel reviews manually is time-consuming and error-prone. However, with data mining techniques, it is possible to "harvest" and analyse thousands of reviews in a relatively short time. This study provides useful implications and guidelines for hotel practitioners on how customer reviews can be evaluated using text mining with open source and free software.

\section{References}

1. Ajanovic, E., Çizel B., \& Çizel R. (2018). Nitel İçerik Analizi Üzerine Bir Yazın Taraması. In Demirkaya, H., Direkçi, B., Eraslan, M., Kılınç, M., (eds.). (2018). Disiplinlerarası Akademike Calısmalar II, Ankara, Turkey: Gece Kitaplığı, 385-394.

2. Alaei, A. R., Becken, S., \& Stantic, B. (2019). Sentiment analysis in tourism: capitalizing on big data. Journal of Travel Research, 58(2), 175-191. DOI:10.1177/0047287517747753

3. Al-Daihani, S. M., \& Abrahams, A. (2016). A text mining analysis of academic libraries' tweets. The Journal of Academic Librarianship, 42(2), 135-143. DOI: 10.1016/i.acalib.2015.12.014

4. Al Mana, A. M., \& Mirza, A. A. (2013). The impact of electronic word of mouth on consumers' purchasing decisions. International Journal of Computer Applications, 82(9), 23-31. DOI: $\underline{10.5120 / 14145-2286}$

5. Anderson, E. W. (1998). Customer satisfaction and word of mouth. Journal of Service Research, 1(1), 5-17. DOI: $10.1177 / 109467059800100102$

6. Arndt, J. (1967). Role of product-related conversations in the diffusion of a new product. Journal of Marketing Research, 4(3), 291-295. DOI: $10.1177 / 002224376700400308$

7. Aureli, S., Medei, R., Supino, E., \& Travaglini, C. (2017). Sustainability disclosure and a legitimacy crisis: Insights from two major cruise companies. European Journal of Tourism Research, 17, 149-163.

8. Attila, A.T. (2016) The Impact of the Hotel Industry on the competitiveness of Tourism Destinations in Hungary, Journal of Competitiveness, 8 (4), 85-104. DOI:10.7441/joc.2016.04.06.

9. Belarmino, A., Whalen, E., Koh, Y., \& Bowen, J. T. (2019). Comparing guests' key attributes of peer-to-peer accommodations and hotels: mixed-methods approach. Current Issues in Tourism, 22(1), 1-7. DOI: 10.1080/13683500.2017.1293623

10. Bickart, B., \& Schindler, R. M. (2001). Internet forums as influential sources of consumer information. Journal of Interactive Marketing, 15(3), 31-40. DOI: 10.1002/dir.1014

11. Bjørkelund, E., Burnett, T. H., \& Nørvåg, K. (2012). A study of opinion mining and visualization of hotel reviews. Paper presented at 14th International Conference on Information Integration and Web-based Applications \& Services, $3^{\text {rd }}-5^{\text {th }}$ December 2012, Bali, Indonesia. 


\section{JOURNAL OF TOURISM AND SERVICES}

Issuxe 21, volume 11, ISSN 1804-5650 (Online)

wwxw.jots.cz

12. Boyd, D. M., \& Ellison, N. B. (2007). Social network sites: Definition, history, and scholarship. Journal of Computer-mediated Communication, 13(1), 210-230. DOI: 10.1111/j.10836101.2007.00393.x

13. Bryman, A. (2012). Social research methods. (4th Edition). Oxford, UK: Oxford University Press.

14. Bucur, C. (2015). Using opinion mining techniques in tourism. Procedia Economics and Finance, 23, 1666-1673. DOI: 10.1016/S2212-5671(15)00471-2

15. Buttle, F. A. (1998). Word of mouth: understanding and managing referral marketing. Journal of Strategic Marketing, 6(3), 241-254. DOI: 10.1080/096525498346658

16. Cajachahua, L., \& Burga, I. (2017). Sentiments and opinions from Twitter about Peruvian touristic places using correspondence analysis. Paper presented at Symposium on Information Management and Big Data. $4^{\text {th }}-6^{\text {th }}$ September 2017, Lima, Peru. (pp. 178-189).

17. Catahan, N., \& Woodruffe-Burton, H. (2019). The view, brew and loo: perceptions of botanic gardens? Journal of Place Management and Development, 12(1), 20-38. DOI: 10.1108/JPMD-12-2017$\underline{0127}$

18. Cha, M., Kwak, H., Rodriguez, P., Ahn, Y. Y., \& Moon, S. (2007). I tube, you tube, everybody tubes: analyzing the world's largest user generated content video system. Paper presented at Proceedings of the 7 th ACM SIGCOMM conference on Internet measurement, $24^{\text {th }}-26^{\text {th }}$ October 2007, San Diego California, USA.

19. Cheng, M., \& Foley, C. (2018). The sharing economy and digital discrimination: The case of Airbnb. International Journal of Hospitality Management, 70, 95-98. DOI: $\underline{10.1016 / \mathrm{j} .1 \mathrm{ijhm} .2017 .11 .002}$

20. Cheng, M., \& Jin, X. (2019). What do Airbnb users care about? An analysis of on-line review comments. International Journal of Hospitality Management, 76, 58-70. DOI:10.1016/i.ijhm.2018.04.004

21. Claster, W.B.,Pardo, P., Cooper M., \& K. Tajeddini. (2013). Tourism, travel and tweets: Algorithmic text analysis methodologies in tourism. Middle East Journal of Management, 1(1), 81-99.

22. Clausen, S. E. (1998). Applied correspondence analysis: An introduction (Vol. 121). New York: Sage.

23. Çakır, F., Aybar, N., \& Akel, G. (2017). E-wom'un tüketicilerin tatil satın alma niyetine etkisi. Adnan Menderes Üniversitesi Sosyal Bilimler Enstitüsü Dergisi,4(4), 110-127. DOI: $\underline{10.30803 / \text { adusobed. } 356180}$

24. Çizel, R. B., Çizel, B., Sarvan, F., \& Özdemır, B. (2013). Emergence and spread of an all-inclusive system in the Turkish Tourism Sector and Strategic Responses of Accommodation Firms. International Journal of Hospitality \& Tourism Administration, 14(4), 305-340. DOI: $\underline{10.1080 / 15256480.2013 .838083}$

25. Damasio, A. R. (2004). Emotions and feelings. Cambridge, UK: Cambridge University Press.

26. Daugherty, T., Eastin, M. S., \& Bright, L. (2008). Exploring consumer motivations for creating user-generated content. Journal of Interactive Advertising, 8(2), 16-25. DOI: $\underline{10.1080 / 15252019.2008 .10722139}$

27. Dhaoui, C., Webster, C. M., \& Tan, L. P. (2017). Social media sentiment analysis: lexicon versus machine learning. Journal of Consumer Marketing, 34(6), 480-488. DOI: 10.1108/JCM-03-2017-2141

28. Dichter, E. (1966). How word-of-mouth advertising works. Harvard Business Review, 44(6), 147160.

29. Dickinger, A., \& Lalicic, L. (2016). An analysis of destination brand personality and emotions: a comparison study. Information Technology \& Tourism, 15(4), 317-340. DOI: 10.1007/s40558-0150044-x

30. Ekman, P. (1992). An argument for basic emotions. Cognition \& Emotion, 6(3-4), 169-200. DOI: $\underline{10.1080 / 02699939208411068}$ 


\section{JOURNAL OF TOURISM AND SERVICES}

Issuxe 21, volume 11, ISSN 1804-5650 (Online)

wwxw.jots.cz

31. Fiske, S. T. (1980). Attention and weight in person perception: The impact of negative and extreme behavior. Journal of Personality and Social Psychology, 38(6), 889. DOI: 10.1037/0022$\underline{3514.38 .6 .889}$

32. Fredrickson, B. L. (1998). What good are positive emotions?. Review of General Psychology, 2(3), 300319. DOI: $10.1037 / 1089-2680.2 .3 .300$

33. Fredrickson B. L. (2001). The role of positive emotions in positive psychology. The broadenand-build theory of positive emotions. The American Psychologist, 56(3), 218-226. DOI: 10.1037//0003-066x.56.3.218.

34. Fredrickson, B. L., \& Losada, M. F. (2005). Positive affect and the complex dynamics of human flourishing. American Psychologist, 60(7), 678. DOI: 10.1037/0003-066X.60.7.678

35. Gan, Q., Ferns, B. H., Yu, Y., \& Jin, L. (2017). A text mining and multidimensional sentiment analysis of on-line restaurant reviews. Journal of Quality Assurance in Hospitality \& Tourism, 18(4), 465-492.

36. Ganu, G., Elhadad, N., \& Marian, A. (2009). Beyond the stars: improving rating predictions using review text content. Paper presented at WebDB. 28 June, 2009, Rhode Island, USA

37. Gilbert, D., \& Abdullah, J. (2004). Holidaytaking and the sense of well-being. Annals of Tourism Research, 31(1), 103-121. DOI: 10.1016/j.annals.2003.06.001

38. Gräbner, D., Zanker, M., Fliedl, G., \& Fuchs, M. (2012). Classification of customer reviens based on sentiment analysis. Paper presented at ENTER January $25^{\text {th }}-27^{\text {th }} 2012$, Helsingborg, Sweden.

39. Grasso, F. (2014), Local Governance, Resources and Tourism Promotion: The Case of Taormina, Economics and Sociology, 7(3): 170-178. DOI: 10.14254/2071-789X.2014/7-3/13

40. Guerreiro, J., \& Moro, S. (2017). Are Yelp's tips helpful in building influential consumers?. Tourism Management Perspectives, 24, 151-154. DOI: 10.1016/i.tmp.2017.08.006

41. Henning-Thurau, T., Gwinner, K. P., Walsh, G., \& Gremler, D. D. (2004). Electronic word-ofmouth via consumer-opinion platforms: what motivates consumers to articulate themselves on the internet? Journal of Interactive Marketing, 18(1), 38-52. DOI: $10.1002 /$ dir.10073

42. Hyoel, K. (2018). Limits of the Bing, AFINN, and NRC Lexicons with the Tidytext Package in R. URL: $\quad$ https://hoyeolkim.wordpress.com/2018/02/25/the-limits-of-the-bing-afinn-and-nrclexicons-with-the-tidytext-package-in-r/ (Accessed on 15.02.2020)

43. Ibrahim, E. E., \& Gill, J. (2005). A positioning strategy for a tourist destination, based on analysis of customers' perceptions and satisfactions. Marketing intelligence \& Planning, 23 (2): 172-88

44. Jalilvand, M. R., \& Samiei, N. (2012). The impact of electronic word of mouth on a tourism destination choice. Internet Research, 22 (5): 591-612. DOI: 10.1108/10662241211271563

45. Kaplan, A. M., \& Haenlein, M. (2010). Users of the world, unite! The challenges and opportunities of Social Media. Business Horizons, 53(1), 59-68. DOI: 10.1016/j.bushor.2009.09.003

46. Kasper, W., \& Vela, M. (2011). Sentiment analysis for hotel reviews. Presented at Computational linguistics-applications conference $17^{\text {th }}-19^{\text {th }}$ October 2011, Jachranka, Poland.

47. Kasper, W., Vela, M., Fuchs, M., Ricci, F., \& Cantoni, L. (2012). Monitoring and summarization of hotel reviews. Paper presented at ENTER January $25^{\text {th }}-27^{\text {th }} 2012$, Helsingborg, Sweden.

48. Kim, K., Park, O., Barr, J., \& Yun, H. (2019). Tourists' shifting perceptions of UNESCO heritage sites: lessons from Jeju Island-South Korea. Tourism Review, 74(1), 20-29. DOI: 10.1108/TR-09$\underline{2017-0140}$

49. Kozak, M. (2007). Turizm sektöründe tüketicilerin şikâyetlerini bildirme eğilimleri. Yönetim ve Ekonomi: Celal Bayar Üniversitesi İktisadi ve İdari Bilimler Fakültesi Dergisi, 14(1), 137-151.

50. Lau, K. N., Lee, K. H., \& Ho, Y. (2005). Text mining for the hotel industry. Cornell Hotel and

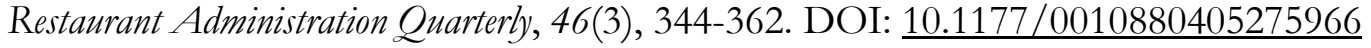




\section{JOURNAL OF TOURISM AND SERVICES}

Issuxe 21, volume 11, ISSN 1804-5650 (Online)

wwxw.jots.cz

51. Law, R., Leung, R., \& Buhalis, D. (2009). Information technology applications in hospitality and tourism: a review of publications from 2005 to 2007. Journal of Travel \& Tourism Marketing, 26(56), 599-623. DOI: $10.1080 / 10548400903163160$

52. Lee, M., Jeong, M., \& Lee, J. (2017). Roles of negative emotions in customers' perceived helpfulness of hotel reviews on a user-generated review website: a text mining approach. International Journal of Contemporary Hospitality Management, 29(2), 762-783. DOI: 10.1108/IJCHM$\underline{10-2015-0626}$

53. Li, Y. R., Lin, Y. C., Tsai, P. H., \& Wang, Y. Y. (2015). Traveller-generated contents for destination image formation: Mainland China travellers to Taiwan as a case study. Journal of Travel \& Tourism Marketing, 32(5), 518-533. DOI: 10.1080/10548408.2014.918924

54. Ma, Y., \& Li, S. (2016). The effect of negative affects varying in motivational intensity on attentional flexibility. Cogent Psychology, 3(1), 1-7. DOI: $10.1080 / 23311908.2016 .1209800$

55. Marcus, G. E., \& MacKuen, M. B. (1993). Anxiety, enthusiasm, and the vote: The emotional underpinnings of learning and involvement during presidential campaigns. American Political Science Review, 87(3), 672-685. DOI: 10.2307/2938743

56. Maric, D., Marinkovic, V., Maric, R., \& Dimitrovski, D. (2016). Analysis of tangible and intangible hotel service quality components. Industrija, 44(1), 7-25. DOI: 10.5937/industrija1-8437

57. Markopoulos, G., Mikros, G., Iliadi, A., \& Liontos, M. (2015). Sentiment analysis of hotel reviews in Greek: a comparison of unigram features. In Vicky Katsoni (eds.) (2015). Cultural Tourism in a Digital Era. Switzerland: Springer, Cham, 373-383.

58. Marrese-Taylor, E., Velásquez, J. D., Bravo-Marquez, F., \& Matsuo, Y. (2013). Identifying customer preferences about tourism products using an aspect-based opinion mining approach. Procedia Computer Science, 22, 182-191. DOI: 10.1016/j.procs.2013.09.094

59. Mir, I. A., \& U.R. Rehman, K. (2013). Factors affecting consumer attitudes and intentions toward user-generated product content on YouTube. Management \& Marketing, 8(4).

60. Misopoulos, F., Mitic, M., Kapoulas, A., \& Karapiperis, C. (2014). Uncovering customer service experiences with Twitter: The case of airline industry. Management Decision, 52(4), 705-723. DOI: 10.1108/MD-03-2012-0235

61. Nawijn, J. (2011). Determinants of daily happiness on vacation. Journal of Travel Research, 50(5), 559-566. DOI: $10.1177 / 0047287510379164$

62. Nave, M., Rita, P., \& Guerreiro, J. (2018). A decision support system framework to track consumer sentiments in social media. Journal of Hospitality Marketing \& Management, 27(6), 693710. DOI: $10.1080 / 19368623.2018 .1435327$

63. Neidhardt, J., Rümmele, N., \& Werthner, H. (2017). Predicting happiness: user interactions and sentiment analysis in an online travel forum. Information Technology \& Tourism, 17(1), 101-119. DOI: $10.1007 / \mathrm{s} 40558-017-0079-2$

64. Neundorf, K. (2002). The Content Analysis Guidebook. California, USA: Thousands Oaks: Sage.

65. Ozdemir, B., Aksu, A., Ehtiyar, R., Çizel, B., Çizel, R. B., \& İçigen, E. T. (2012). Relationships among tourist profile, satisfaction and destination loyalty: Examining empirical evidences in Antalya region of Turkey. Journal of Hospitality Marketing \& Management, 21(5), 506-540. DOI: 10.1080/19368623.2012.626749

66. Park, D. H., Lee, J., \& Han, I. (2007). The effect of on-line consumer reviews on consumer purchasing intention: The moderating role of involvement. International Journal of Electronic Commerce, 11(4), 125-148. DOI: 10.2753/JEC1086-4415110405 


\section{JOURNAL OF TOURISM AND SERVICES}

Issuxe 21, volume 11, ISSN 1804-5650 (Online)

wwxw.jots.cz

67. Park, S. B., Jang, J., \& Ok, C. M. (2016). Analyzing Twitter to explore perceptions of Asian restaurants. Journal of Hospitality \& Tourism Technology, 7(4), 405-422. DOI: 10.1108/JHTT-082016-0042

68. Poon, A. (1993). Tourism, technology and competitive strategies. CAB international.

69. Plutchik, R., (1980). Emotion: A Psychoevolutionary Synthesis, New York: Harper \& Row.

70. Rogger W. (2018). Price of Travel, 23 Europe All-inclusive resort destinations from cheapest to most expensive, https://www.priceoftravel.com/9078/europe-all-inclusive-resort-destinationsfrom-cheapest-to-most-expensive/ (Accessed on 20.01.2020)

71. Rossetti, M., Stella, F., \& Zanker, M. (2016). Analyzing user reviews in tourism with topic models. Information Technology \& Tourism, 16(1), 5-21. DOI: 10.1007/s40558-015-0035-y

72. Salkind, N. J. (Ed.). (2010). Encyclopedia of research design(Vol. 1). Sage.

73. Schreier, M. (2014). Ways of doing qualitative content analysis: Disentangling terms and terminologies. Forum: Qualitative Social Research, 15(1), 1-27. DOI: 10.17169/fqs-15.1.2043

74. Serna, A., Gerrikagoitia, J. K., \& Alzua, A. (2013). Towards a better understanding of the cognitive destination image of Euskadi-Basque Country based on the analysis of UGC. In Information and communication technologies in tourism 2014(pp. 395-407). Springer, Cham.

75. Serna, A., Gerrikagoitia, J. K., \& Bernabé, U. (2016). Discovery and classification of the underlying emotions in the user generated content (UGC). Paper presented at Information and communication technologies in Tourism 2016.2nd-5th February, 2016, Bilbao, Spain.

76. Shields, G. S., Sazma, M. A., \& Yonelinas, A. P. (2016). The effects of acute stress on core executive functions: A meta-analysis and comparison with cortisol. Neuroscience and Biobehavioral Reviews, 68, 651-668. DOI: 10.1016/i.neubiorev.2016.06.038

77. Shimada, K., Inoue, S., Maeda, H., \& Endo, T. (2011). Analyzing tourism information on Twitter for a local city. Paper presented at the First ACIS International Symposium on Software and Network Engineering (SSNE). $19^{\text {th }}-20^{\text {th }}$ December 2011, Seoul, South Korea.

78. Singh, J. (1988). Consumer complaint intentions and behavior: definitional and taxonomical issues. Journal of Marketing, 52(1), 93-107. DOI: 10.2307/1251688

79. Sirgy, M.J. (2019). Promoting quality-of-life and well-being research in hospitality and tourism. Journal of Travel \& Tourism Marketing, 36(1), 1-13. DOI: $10.1080 / 10548408.2018 .1526757$

80. Smith, A. N., Fischer, E., \& Yongjian, C. (2012). How does brand-related user-generated content differ across YouTube, Facebook, and Twitter?. Journal of Interactive Marketing, 26(2), 102-113. DOI: $\underline{10.1016 / \text { i.intmar.2012.01.002 }}$

81. Sun, N., Liu, D., Zhu, A., Chen, Y., \& Yuan, Y. (2019). Do Airbnb's "Superhosts" deserve the badge? An empirical study from China. Asia Pacific Journal of Tourism Research, 24(4), 296-313. DOI: $\underline{10.1080 / 10941665.2018 .1564342}$

82. Suttles, J., \& Ide, N. (2013). Distant supervision for emotion classification with discrete binary values. In International Conference on Intelligent Text Processing and Computational Linguistics.14th International Conference, CICLing. 24th-30th March, 2013, Samos, Greece.

83. Taboada, M., Brooke, J., Tofiloski, M., Voll, K., \& Stede, M. (2011). Lexicon-based methods for sentiment analysis. Computational Linguistics, 37(2), 267-307. DOI: 10.1162/COLI a 00049

84. Tan, S., \& Wu, Q. (2011). A random walk algorithm for automatic construction of domainoriented sentiment lexicon. Expert Systems with Applications, 38(10), 12094-12100. DOI: doi.org/10.1016/j.eswa.2011.02.105

85. Tao, S., \& Kim, H. S. (2019). Cruising in Asia: what can we dig from on-line cruiser reviews to understand their experience and satisfaction. Asia Pacific Journal of Tourism Research, 24(6), 514-528. DOI: $\underline{10.1080 / 10941665.2019 .1591473}$ 


\section{JOURNAL OF TOURISM AND SERVICES}

Issuxe 21, volume 11, ISSN 1804-5650 (Online)

wwxw.jots.cz

86. Toral, S. L., Martínez-Torres, M. R., \& Gonzalez-Rodriguez, M. R. (2018). Identification of the unique attributes of tourist destinations from on-line reviews. Journal of Travel Research, 57(7), 908919. DOI: doi.org/10.1177/0047287517724918

87. Tromp, E., \& Pechenizkiy, M. (2014). Rule-based Emotion Detection on Social Media: Putting Tweets on Plutchik's Wheel. ArXiv, abs/1412.4682.

88. Tung, V. W. S., \& J. B. Ritchie. (2011). "Exploring the Essence of Memorable Tourism Experiences." Annals of Tourism Research 38 (4): 1367-86.

89. Tussyadiah, I. P., \& Park, S. (2018). When guests trust hosts for their words: Host description and trust in sharing economy. Tourism Management, 67, 261-272. DOI: 10.1016/i.tourman.2018.02.002

90. Tussyadiah, I. P., \& Zach, F. (2017). Identifying salient attributes of peer-to-peer accommodation experience. Journal of Travel \& Tourism Marketing, 34(5), 636-652. DOI: $\underline{10.1080 / 10548408.2016 .1209153}$

91. UNWTO. (2019). International Tourism Highlights 2019 Edition.

92. Ullah, R., Amblee, N., Kim, W., \& Lee, H. (2016). From valence to emotions: Exploring the distribution of emotions in on-line product reviews. Decision Support Systems, 81, 41-53. DOI: 10.1016/i.dss.2015.10.007

93. Qi, S., Wong, C. U. I., Chen, N., Rong, J., \& Du, J. (2018). Profiling Macau cultural tourists by using user-generated content from on-line social media. Information Technology \& Tourism, 20(1-4), 217-236. DOI: $10.1007 / \mathrm{s} 40558-018-0120-0$

94. Verhellen, Y., Dens, N., \& De Pelsmacker, P. (2013). Consumer responses to brands placed in Youtube movies: The effect of prominence and celebrity endorser expertise. Journal of Electronic Commerce Research.-Long Beach, Calif., 14(4), 287-303.

95. Watson, D., Clark, L. A., \& Carey, G. (1988). Positive and negative affectivity and their relation to anxiety and depressive disorders. Journal of Abnormal Psychology, 97(3), 346-353. DOI: $\underline{10.1037 / / 0021-843 x .97 .3 .346}$

96. Wickham, H. (2019). Easily Harvest (Scrape) Web Pages. URL: https://cran.rproject.org/web/packages/rvest/rvest.pdf (Accessed on 20.01.2020)

97. Wickham, H. (2014). rvest: easy web scraping with R. URL: https://blog.rstudio.com/2014/11/24/rvest-easy-web-scraping-with-r/ (Accessed on 20.01.2020)

98. Wong, C. U. I., \& Qi, S. (2017). Tracking the evolution of a destination's image by text-mining on-line reviews-the case of Macau. Tourism Management Perspectives, 23, 19-29. DOI: $\underline{10.1016 / \mathrm{i} . \mathrm{tmp} .2017 .03 .009}$

99. Xiang, Z., Schwartz, Z., Gerdes Jr, J. H., \& Uysal, M. (2015). What can big data and text analytics tell us about hotel guest experience and satisfaction?. International Journal of Hospitality Management, 44, 120-130. DOI: 10.1016/j.ijhm.2014.10.013

100. Yagi, C., \& Pearce, P. L. (2018). European Castles through Japanese Eyes and Minds. European Journal of Tourism Research, 19, 5-22.

101. Yan, Q., Zhou, S., \& Wu, S. (2018). The influences of tourists' emotions on the selection of electronic word of mouth platforms. Tourism Management, 66, 348-363. DOI: 10.1016/i.tourman.2017.12.015

102. Yin, D., Bond, S., \& Zhang, H. (2014). Anxious or angry? Effects of discrete emotions on the perceived helpfulness of on-line reviews. MIS Quarterly, 38(2), 539-560. DOI: $\underline{10.25300 / \mathrm{MISQ} / 2014 / 38.2 .10}$ 


\section{JOURNAL OF TOURISM AND SERVICES}

Issuxe 21, volume 11, ISSN 1804-5650 (Online)

wwxw.jots.cz

103. Yüksel, A., \& Yüksel, F. (2007). Shopping risk perceptions: Effects on tourists' emotions, satisfaction and expressed loyalty intentions. Tourism Management, 28(3), 703-713. DOI: 10.1016/j.tourman.2006.04.025

104. Zhang, Z., Ye, Q., Zhang, Z., \& Li, Y. (2011). Sentiment classification of Internet restaurant reviews written in Cantonese. Expert Systems with Applications, 38(6), 7674-7682. DOI: $\underline{10.1016 / j . e s w a .2010 .12 .147}$

105. Zhang, W., Kang, L., Jiang, Q., \& Pei, L. (2018). From buzz to bucks: The impact of social media opinions on the locus of innovation. Electronic Commerce Research and Applications, 30, 125-137. DOI: $10.1016 /$ i.elerap.2018.04.004

106. Zheng, Z., Ma, Y., Zheng, H., Ju, J., \& Lin, M. (2018). UGC: Real-time, ultra-robust feature correspondence via unilateral grid-based clustering. IEEE Access, 6, 55501-55508. DOI: 10.1109/ACCESS.2018.2871729

107. Zins, A. H. (2002). Consumption emotions, experience quality and satisfaction: a structural analysis for complainers versus non-complainers. Journal of Travel \& Tourism Marketing, 12(2-3), 318. DOI: $10.1300 / \mathrm{J} 073 \mathrm{v} 12 \mathrm{n} 0202$

\section{Brief description of Authors:}

\section{Leyla Atabay}

Student at Akdeniz University Tourism Faculty in Antalya, Turkey. Web: turizm.akdeniz.edu.tr - email: leylaatabay88@gmail.com.She graduated from Nevsehir University - Tourism Management Department (2012). She received her MSc in Tourism and Hotel Management from Akdeniz University (2019). Her major interests are on-line tourist behavior and innovation in tourism.

\section{Beykan Çizel}

Full-professor at Akdeniz University Tourism Faculty in Antalya, Turkey. Web: turizm.akdeniz.edu.tr email: beykan@akdeniz.edu.tr. He graduated from Bilkent University Tourism and Hotel Management Department (1996). He received his MSc in Tourism and Hotel Management from Akdeniz University (1999), and his Ph.D. in Business Administration from Akdeniz University (2005). His major interests are tourism and hotel management, social psychology, and e-tourist behavior. 